\title{
Nanocomposites for Decontamination of Multicomponent Technogenic Dilutions
}

\author{
V. KADOSHNIKOV ${ }^{1}$, YU. LYTVYNENKO ${ }^{1}$, YU. ZABULONOV ${ }^{1}$ AND V. \\ KRASNOHOLOVETS ${ }^{2}$ \\ ${ }^{1}$ Institute of Environmental Geochemistry under Natl. Acad. Sci. and Ministry \\ for Emergencies and Affairs of Population Protection from the Consequences of \\ Chornobyl Catastrophe, 34-a Acad. Palladin Ave., UA-03680, Kyiv, Ukraine \\ ${ }^{2}$ Institute of Physics, Natl. Acad. Sci., Prospect Nauky 46, UA-03028 Kyiv, Ukraine
}

\section{Email: krasnoh@iop.kiev.ua}

Received: October 25, 2014 IRevised: January 04, 2015 IAccepted: March 09, 2015

Published online: February 08, 2016, The Author(s) 2016. This article is published with open access at www.chitkara.edu.in/publications

\begin{abstract}
Employing model solutions we have tested a new technological method of neutralization of multi-metal containing effluences including low radioactive ones. The proposed approach seamlessly combines the positive properties of both physical chemical methods and nanotechnology using silica-magnetite nanocomposite $\mathrm{SiO}_{2} / \mathrm{Fe}_{3} \mathrm{O}_{4}$ that is synthesized directly in the man-caused polluted solution (the so-called method of direct sedimentation). The novelty of the method is the absorption of pollutants by the whole volume of synthesized nanoparticles in addition to the absorption of the particles' surface. After separation of the solid and liquid phases, about $75 \% \mathrm{Cs}, 93 \%$ $\mathrm{Sr}, 97 \% \mathrm{Cu}$ and $99 \% \mathrm{Fe}^{+2} / \mathrm{Fe}^{+3}$ pass from the dispersion medium into a solid phase per one loop. The obtained $\mathrm{SiO}_{2} / \mathrm{Fe}_{3} \mathrm{O}_{4}$ nanocomposite heated to 1000 ${ }^{\circ} \mathrm{C}$ forms a small size glass phase, which is a reliable matrix for the longterm retention of radionuclides incorporated in the composite's volume. Thus the approach will allow one to reduce the collected radioactive isotopes to a tiny volume, which means the decrease of land and funds needed to burial radioactive waste.
\end{abstract}

Kewords: decontamination, technological solutions, nanocomposite, sorbent, heavy metals, radionuclides, polluted water, heterocoagulation, vitrification

Journal of Nuclear

Physics, Material Sciences, Radiation and Applications [Vol-3, No-2

Feburary 2016 pp. 279-292 
Kadoshnikov, V Lytvynenko, Yu Zabulonov, $\mathrm{Yu}$ Krasnoholovets, V

\section{INTRODUCTION}

Among recent publications we have to mention a system of wastewater treatment developed by Patzay et al. [4] in which they used a cesium selective inorganic ion exchanger. They separated selectively cesium $\left({ }^{137} \mathrm{Cs},{ }^{134} \mathrm{Cs}\right)$ from high salt concentration and strongly alkaline evaporator bottom residue in Paks Nuclear Power Plant (Hungary) reaching a volume reduction factor about 1800-3500 at the value of the decontamination factor DF $>100$, for the samples of four tanks of the mentioned plant.

Crystalline silicoti-tanates (CSTs) are a new class of ion exchangers that were jointly invented by researchers at Sandia National Laboratories and Texas A\&M University. Tests performed at numerous locations with early lab-scale TAM-5 samples established the material as a leading candidate for treating radioactive waste volumes such as those found at the Hanford site in Washington. Thus Sandia developed a Cooperative Research and Development Agreement (CRADA) partnership with UOP, a world leader in developing, commercializing, and supplying adsorbents.

Abdel Rahman et al. [13] describe advances in conventional treatment of aqueous radioactive wastes, advances in conventional treatment of organic liquid wastes, and emerged technological options. Among major methods of purification of radionuclides are liquid-liquid extraction [7, 5], solid phase extraction by using sorbents [8, 18], ion exchangers of various types $[1,14]$, which in particular possess also sorbent properties [6] and ion exchange resins [10], and reductants of an organic base [9].

Valdovinos et al. [16] review treatment methods for radioactive liquid wastes and their electrochemical applications considering such approaches as: ion exchange/sorption, chemical precipitation, evaporation or ultrafiltration/ reverse osmosis. Nevertheless, they emphasise that liquid containing suspended matter must be treated to remove the particulates before primary treatment or after it. Sedimentation, decantation, filtration or centrifugation are treatments used commonly to clear the effluent wastes or to remove miscellaneous debris or insoluble particles.

A new class of ion exchangers, which were jointly invented by researchers at Sandia National Laboratories and Texas A\&M University, have been planned to use to clean wastewater at the Fukushima reactor destroyed by the tsunami in 2011 [2]. Crystalline silicoti-tanates are considered by them also as a leading candidate for treating radioactive waste volumes such as those found at the Hanford site in Washington.

Kovař́k et al. [11] performed a literature review for the molten salt oxidation technology in order to collect all available scientific and engineering 
information for further use of this technology in the nuclear field for radioactive waste treatment.

At the same time none of the protection technologies provide a sufficiently effective level of decontamination of multicomponent man-triggered dilutions. They are often not only imperfect and have low efficiency, high power consumption and cost, but also generate a significant amount of secondary waste that is as dangerous as the original, because it represents an imminence of secondary contamination.

There is a particularly urgent need for new technologies to clean multicomponent man-triggered dilutions containing toxic elements, ions of heavy metals and radionuclides. New approaches must seamlessly combine positive properties of both traditional physical-chemical methods and nanotechnologies. A balanced combination of several effective treatment processes of mantriggered polluted water, the use of physical factors - pulsed magnetic field, together with a chemical method - the synthesis of nanocomposites, as well as waste disposal, could solve the problems of water management and significantly improve the environmental safety of industrial plants [3].

For the decontamination of man-made solutions, particularly multi-metal and low radioactive effluents, various sorbent materials with high porosity are widely used. Such materials provide a more complete contact between the sorbent and the liquid phase. The main drawback of these important traditional methods is the technological complexity and high production cost of such sorbents. However, our study shows that these limitations can be minimised by the use of nano-sized sorbents.

Sorbents with high sorption activity and selectivity possess advanced surfaces through which the interaction of the solid and liquid phase takes place. On the other hand, when sorbents with a ramified specific surface are produced, particles with an increased number of nanocapillaries are formed, which lead to a dramatically slowdown of sorption.

An indicative comparative analysis of multi-component metalcontaminated solutions (liquid radioactive waste) is given in Table 1.

In contrast to the traditional method in which the sorbent is mixed with a solution, in our method a nanoscale sorbent is synthesised directly in the man-caused pollution solution, such that pollutants are used in the formation of composite nanoparticles. Then pollutants of the dispersion medium are adsorbed not only by the nanoparticles' surface, but also by the volume of the synthesised nanoparticles. In our method the volumetric absorption significantly prevails conventional surface sorption. Colloids of polysilicic acids (up to $20 \mathrm{~nm}$ in size) obtained by the polymerisation of silicic acid in the presence of sodium ions [15] are used as such nanoparticles.
Nanocomposites for Decontamination of Multicomponent Technogenic Dilutions 
Kadoshnikov, V Lytvynenko, Yu Zabulonov, Yu Krasnoholovets, V
Table 1: Compare of different methods of radioactive solutions cleaning (here: $\mathrm{A}$ - is very high, $\mathrm{B}$ - high, $\mathrm{C}$ - average, $\mathrm{D}$ - low).

\begin{tabular}{|c|c|c|c|c|c|c|}
\hline Parameter & $\begin{array}{l}\text { Method } \\
\text { Deep } \\
\text { evaporation }\end{array}$ & Coprecipitation & Sorption & $\begin{array}{l}\text { Ion } \\
\text { exchange }\end{array}$ & $\begin{array}{l}\text { Electro } \\
\text { dialysis }\end{array}$ & $\begin{array}{l}\text { Our method } \\
\text { of direct } \\
\text { sedimentation }\end{array}$ \\
\hline $\begin{array}{l}\text { Requirements } \\
\text { for preliminary } \\
\text { preparation }\end{array}$ & $\mathrm{D}$ & $\mathrm{B}$ & $\mathrm{B}$ & B & B & $\mathrm{D}$ \\
\hline Selectivity & $\mathrm{D}$ & A & $\mathrm{C}$ & $\mathrm{C}$ & $\mathrm{C}$ & $\mathrm{D}$ \\
\hline $\begin{array}{l}\text { Obstacles to } \\
\text { removal of } \\
\text { pollutants } \\
\text { (colloidal phase, } \\
\text { complexing } \\
\text { agents, } \\
\text { surfactants, } \\
\text { mechanical } \\
\text { impurities, } \\
\text { temperature) }\end{array}$ & $\mathrm{C}$ & $\mathrm{B}$ & B & B & $\mathrm{B}$ & $\mathrm{D}$ \\
\hline $\begin{array}{l}\text { Completeness of } \\
\text { removal }\end{array}$ & A & B & B & C & $\mathrm{C}$ & B \\
\hline $\begin{array}{l}\text { The need for } \\
\text { additional } \\
\text { reagents }\end{array}$ & $\mathrm{D}$ & $\mathrm{B}$ & $\mathrm{D}$ & $\mathrm{D}$ & $\mathrm{D}$ & $\mathrm{C}$ \\
\hline $\begin{array}{l}\text { The need of } \\
\text { regeneration }\end{array}$ & $\mathrm{D}$ & $\mathrm{D}$ & B & B & B & $\mathrm{D}$ \\
\hline $\begin{array}{l}\text { Energy } \\
\text { consumption }\end{array}$ & $\mathrm{B}$ & $\mathrm{D}$ & $\mathrm{C}$ & $\mathrm{C}$ & $\mathrm{C}$ & D \\
\hline Energy intensity & $\mathrm{D}$ & $\mathrm{C}$ & $\mathrm{C}$ & $\mathrm{C}$ & $\mathrm{C}$ & $\mathrm{C}$ \\
\hline $\begin{array}{l}\text { Possibility } \\
\text { to include in } \\
\text { traditional } \\
\text { schemes }\end{array}$ & $\mathrm{B}$ & $\mathrm{D}$ & $\mathrm{D}$ & $\mathrm{D}$ & $\mathrm{D}$ & B \\
\hline $\begin{array}{l}\text { The ability of } \\
\text { phase formation, } \\
\text { suitable for long } \\
\text { term storage }\end{array}$ & $\mathrm{C}$ & $\mathrm{D}$ & $\mathrm{D}$ & $\mathrm{D}$ & $\mathrm{D}$ & B \\
\hline
\end{tabular}

Polysilicic acids, due to their affinity with the class of cations, can be used as sorbent [12]. The main mechanisms that determine the uptake of cations from the dispersion medium with nanoparticles of polysilicic acids can be identified as follows: (i) the agglutination of cations directly in the process of formation of nanocolloids and (ii) the sorption of cations by the surface of formed colloidal particles. Sodium ion can act as the central coordinating ion at the formation of colloidal particles. 
Our objectives are the demonstration of total sedimentation of radionuclides and/or any kinds of heavy ions by using the new approach of volumetric absorption of peculiar nanocomposites. The phenomenon of volumetric absorption is a real novelty of the present research.

\section{EXPERIMENTAL PART}

\subsection{Equipment}

Our research team has designed a generator of physical fields in which an active part is a container with a volume of about 0.5 litres. A test-tube with the material to be treated can be put in the container. Around the container, induction coils connected to a microprocessor unit are located. An electromagnetic field launched in the setup switches pulses of physical fields that irradiate the material to be treated. In our studies the power density of the fields varied in a wide range, namely, from $5 \mathrm{~mW} \times \mathrm{cm} 2$ to hundreds of $\mathrm{W} \times \mathrm{cm} 2$. The carrier frequency of the pulse modulation varied from $50 \mathrm{~Hz}$ to $20 \mathrm{kHz}$, although the main studies were conducted at a carrier frequency of $4.5 \mathrm{kHz}$, a pulse duration $t=500 \pm 10 \mathrm{~ms}$ and a repetition rate of $1 \pm 0.1 \mathrm{~Hz}$.

For the separation of the solid and liquid phases we used a centrifugemixer, CM-70M-09 (ELMI Latvia).

The content of $\mathrm{Cs}, \mathrm{Sr}, \mathrm{Co}, \mathrm{Cu}$ and $\mathrm{Fe}$ in an aqueous solution was estimated applying the method of atomic absorption by using a spectrophotometer, AA8500 (Japan).

In the process of preparing the necessary solutions we used a shaker, Elpan-357 (Poland), and a pH meter, MI-150 (Muscovy).

The mineral composition of the samples was assessed by X-ray phase analysis using a diffractometer, DRON-3, with the filtered $\mathrm{Cu}_{\mathrm{ka}}$-radiation at a shooting speed of 1-2 min. In cases where the samples included a significant amount of iron we used an X-ray tube with an iron anticathode in the X-ray diffractometer. The measurements were carried out at the anti-cathode voltage of $30 \mathrm{keV}$. IR spectroscopic study conducted by the standard method (pressing the sample in pills of $\mathrm{KBr}$ ), were executed by using a UR-20 spectrophotometer. Optical studies were carried out using an optical reflexive microscope, Unicorn NJF 120A.

A tool TGA Q-50 examined the thermal stability of the silica magnetite composite.

\subsection{Materials}

The following substances pure for analysis and chemically pure have been used: sodium silicate $\mathrm{Na}_{2} \mathrm{SiO}_{3}$, sodium hydroxide $\mathrm{NaOH}$, iron salts $\mathrm{FeSO}_{4}$ and
Nanocomposites for

Decontamination of Multicomponent Technogenic Dilutions 
Kadoshnikov, V Lytvynenko, Yu

Zabulonov, Yu

Krasnoholovets, V
$\mathrm{FeCl}_{3}$, ion-exchange resins (cation exchanger $\mathrm{KU}-2-8$ ), hydrochloric acid $\mathrm{HCl}$, and sulphuric acid $\mathrm{H}_{2} \mathrm{SO}_{4}$.

\subsection{Methods}

To prepare the solution of sodium silicate $\mathrm{Na}_{2} \mathrm{SiO}_{3}$, we calculated an amount of reagent needed to introduce into the necessary amount of distillate and stirred until the complete dissolution of the crystals. The obtained solution can be kept in a bottle of polyethylene terephthalate (PET) under normal conditions within 3 months.

To prepare the solution $\mathrm{Fe}^{2+}$ and $\mathrm{Fe}^{3+}$ we used salt $\mathrm{FeSO}_{4}$ and $\mathrm{FeCl}_{3}$, which in the calculated amounts were dissolved in the required volume of distillate

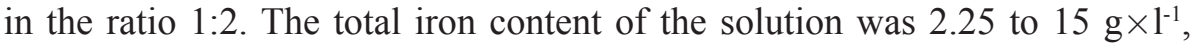
depending on the experimental conditions. The resulting solution can be stored for no more than 12 hours in a glass container under normal conditions. With longer storage a precipitate is formed in the solution, which is associated with the oxidation of $\mathrm{Fe}^{2+}$ to $\mathrm{Fe}^{3+}$.

To obtain a solution of polysilicic acids with the minimal quantity of anions, we used the ion exchange reaction $\mathrm{Na}^{+}$for $\mathrm{H}^{+}$. In our work we have used the cation resin KU-2-8. The quality of the preparation met the requirements specification. The dynamic volumetric capacity of the preparation is $1.93 \mathrm{~g} \times \mathrm{mol}^{-1}$, and the specific volume of the $\mathrm{H}^{+}$-form is 4.62. To obtain $\mathrm{H}^{+}$form, the calculated amount of ion exchange resin KU-2-8 is poured with a certain amount of distilled water, after which the suspension is left for one day to allow for the swelling of the resin particles. After this, the distillate is removed and the resin is poured with the calculated volume of hydrochloric acid of the required concentration. A bulb with the solution is placed on a shaker for two hours, and then left for one day. Then the acid was removed by decantation, and the residue was washed several times with distilled water to $\mathrm{pH}=5$. The prepared resin is stored for 10 days under a layer of wash water. For the preparation of the solution of polysilicic acids we used an ion exchange resulting in the replacement of $\mathrm{Na}^{+}$ion by a $\mathrm{H}^{+}$ion. To do this, 500 $\mathrm{ml}$ of sodium silicate, with the necessary concentration, is mixed with $400 \mathrm{~g}$ of swollen $\mathrm{KU}-2-8$ in $\mathrm{H}^{+}$-form. The resulting suspension was stirred in a shaker for one hour and allowed to stand for 3 days to allow for the ion exchange process. After the exchange the $\mathrm{pH}$ of the liquid that is found above the resin layer becomes equal to $4 \pm 0.2$. The solution of polysilicic acids can stay above the layer of the resin at a temperature from +4 to $+80{ }^{\circ} \mathrm{C}$ for up to 10 days in a bottle of polyethylene terephthalate (PET).

Nanocomposite synthesis is carried out in line with an example given in patent [19]. In the working zone (with a volume $\mathrm{V}=1000 \mathrm{ml}$ ) of a specially 
designed reactor, equipped with a thermostat, stirrer, glass and silver chloride electrodes to control the $\mathrm{pH}$, as well as fitted with a set of induction coils, we introduce $500 \mathrm{ml}$ of an aqueous solution containing $\mathrm{Cs}^{1+}, \mathrm{Sr}^{2+}, \mathrm{Co}^{2+}$ and $\mathrm{Cu}^{2+}$ in the amount of $45-63 \mathrm{mg} \times \mathrm{l}^{-1}$; then the volume is filled with $50 \mathrm{ml}$ of a $4 \%$ solution of sodium silicate. The $\mathrm{pH}$ of such system is $10-11$. After that the temperature of the solution is increased to about $70{ }^{\circ} \mathrm{C}$ and is stirred vigorously (1500-2000 rev./min.) and we add $70 \mathrm{ml}$ of a $4 \%$ solution of silicic acid during one hour. After the introduction of the reagents, the mixture is kept at a temperature of $+70 \pm 5{ }^{\circ} \mathrm{C}$ for two hours to mature a colloid of polysilicic acids. After maturation of the colloid in the reaction mixture we slowly introduce $50 \mathrm{ml}$ of a salt solution of $\mathrm{Fe}^{2+} / \mathrm{Fe}^{3+}$ in a $1: 2$ ratio with a

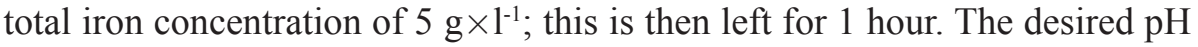
value is adjusted by adding the required amount of an $8 \% \mathrm{NaOH}$ solution to the reaction mixture, so that the $\mathrm{pH}$ of the mixture does not decrease below 9. Throughout the time the solution of iron salts are in the working zone, a pulsed current is applied to the induction coils, which provides a frequency pulse modulation. The resulting system was then cooled for three hours, after which the liquid and solid phases were separated by filtration using the "Blue Ribbon" filter for fine sediments.

The resulting filtrate must be transparent and free of suspended solids. After filtration, the resulting precipitate is dried to a constant weight.

\section{RESULTS}

The scheme of the $\mathrm{SiO}_{2} / \mathrm{Fe}_{3} \mathrm{O}_{4}$ nanocomposite synthesis is shown in Fig. 1 .

According to the conception [12], the formation of colloid of polysilicas occurs by polymerizing the monomer with the production of particles when initially formed molecules $\mathrm{Si}(\mathrm{OH})_{4}$ are condensed, forming colloidal particles and their subsequent growth. The magnitude of the colloidal particles is significantly affected by the acidity of the medium and the relationship between the coordinating atoms (sodium, etc.) and the amount of polysilicic acids.

Sodium cations act as ions forming a "bridge of communication". In the interaction of cations with the silica surface, one or more oxygen atoms of molecules of hydrate water can be replaced by oxygen atoms that belong to the surface of silanol groups $\equiv \mathrm{Si}-\mathrm{OH}$, so that the latter is directly related to the sodium atoms. Therefore, the positive charge of the sodium ion is able to neutralize the negative charge near the adsorbed hydroxyl ion, which determines the charge of the particle and, therefore, can act as a bridging link between two particles of polysilica. In the dispersion medium at $\mathrm{pH}=8.5-9$, silicate ions may exist which contain their cations that must additionally be taken into account.
Nanocomposites for Decontamination of Multicomponent Technogenic Dilutions

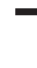


Kadoshnikov, V Lytvynenko, Yu Zabulonov, Yu Krasnoholovets, V

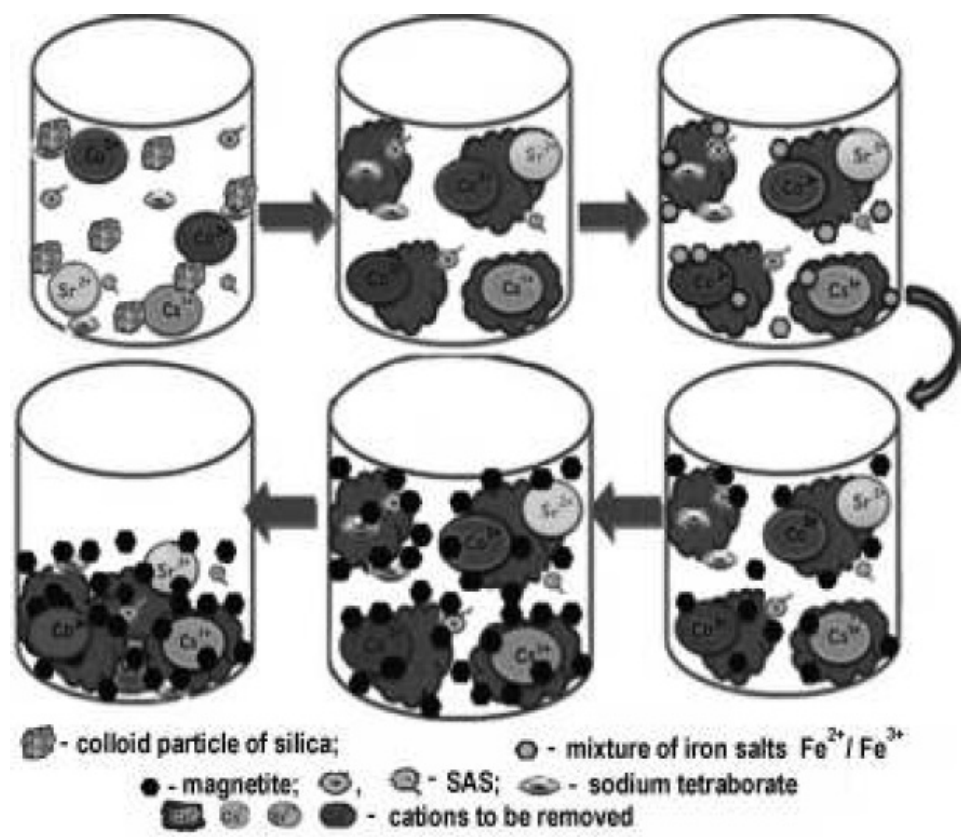

Figure 1: Scheme of synthesis of $\mathrm{SiO}_{2} / \mathrm{Fe}_{3} \mathrm{O}_{4}$ nanocomposite.

Sodium cations as well as alkali cations $\mathrm{Cs}^{1+}$, which are also present in the system, may participate in the formation of the colloidal system and, therefore, pass from the liquid phase into the solid (colloidal) phase.

The participation of alkali metal ions in the formation of colloidal micelles leads to a greater number of connection points. It should also be noted that the ability of metal ions connected to polysilicic acid decreases at its polymerisation, and thus increases the size of the particles. The presence of divalent cations in the dispersion medium $\left(\mathrm{Sr}^{2+}, \mathrm{Co}^{2+}, \mathrm{Cu}^{2+}\right)$ can have a significant impact on micellisation. In addition to single charged alkali metal ions $\left(\mathrm{Na}^{1+}, \mathrm{Cs}^{1+}, \mathrm{K}^{1+}\right.$, etc.), double charged ions of alkaline earth and transition metals $\left(\mathrm{Ca}^{2+}, \mathrm{Sr}^{2+}\right.$, $\mathrm{Cu}^{2+}, \mathrm{Mn}^{2+}$, etc.) at $\mathrm{pH} \approx 9$ can be absorbed and be like positively charged sites on the surface. They may act like bridges connecting two silica particles at their points of contact.

At certain thermodynamic conditions polysilicic acids react with metal cations that are in this solution, so that a part of these cations are involved directly in the scope of the colloidal particles, and some can be adsorbed by the surface of each of the particles. Thus obtained nanoparticles form a thermodynamic non-equilibrium, but a kinetically stable system. For the deposition of this dispersion of nanoparticles obtained from polysilicas, we 


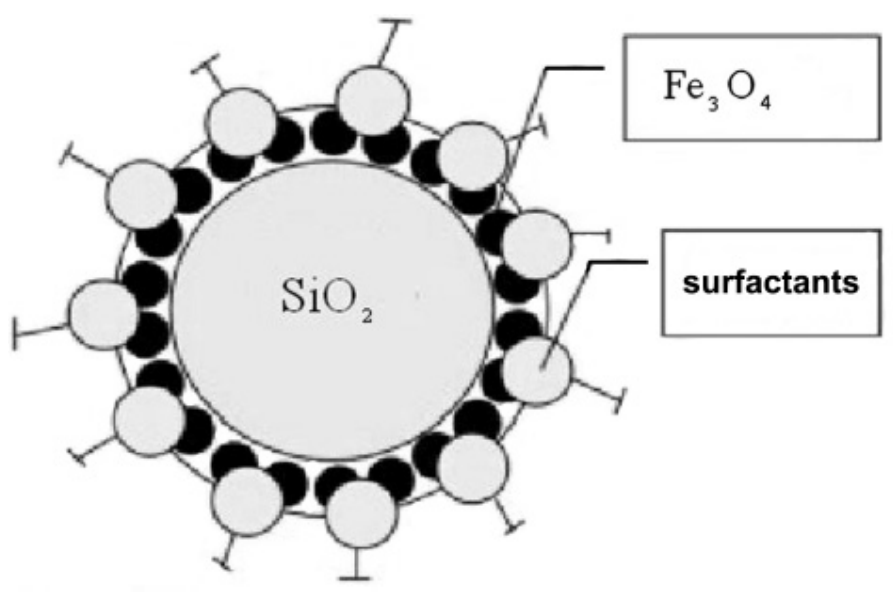

Nanocomposites for

Decontamination of Multicomponent

Technogenic

Dilutions

Figure 2: Schematic structure of a particle of the $\mathrm{SiO}_{2} / \mathrm{Fe}_{3} \mathrm{O}_{4}$ nano-size composite.

propose to use the heterocoagulation process of nanoparticles with opposite charges, particularly for this purpose can be used nanoparticles of magnetite synthesised in the same solution at a $\mathrm{pH}>9$ [20].

Silicon magnetite nanocomposite $\mathrm{SiO}_{2} / \mathrm{Fe}_{3} \mathrm{O}_{4}$ obtained by our method [21] is an artificial nanoscale polymineral material. This polymineral material is formed by the heterocoagulation of particles of polysilicas by using the dispersion of magnetite (Fig. 2).

It is advisable to carry out the synthesis of nanocomposite using a pulsed magnetic field (or a combination of different physical fields). The application of such field/fields can be useful for the formation of magnetite nanoparticles with desired properties. In particular, there is the possibility of obtaining nanodispersed magnetite not only with an increased number of $\mathrm{OH}$ groups, but also with hydrated ferric oxide $\mathrm{Fe}_{2} \mathrm{O}_{3} \times n \mathrm{H}_{2} \mathrm{O}$ on their surface. The presence of $\mathrm{OH}$ groups on the surface of magnetite enhances its sorption activity and, consequently, contributes to the formation of coordination bonds between magnetite and the ligands of the dispersion medium. At such conditions, magnetite nanoparticles produced owing to an "electromagnetic jolting" are in competition with the surface adsorption of the silica particles and the actual growth of the particles themselves. Thus the influence of pulses of physical fields is a factor that contributes to the predominant precipitation of magnetite particles on the silica surface (Fig. 3).

Our studies show (Fig. 4) that after separation of the solid and liquid phases a significant portion of the dispersion medium pollutants have passed into the solid phase. 
Kadoshnikov, V Lytvynenko, Yu Zabulonov, Yu Krasnoholovets, V

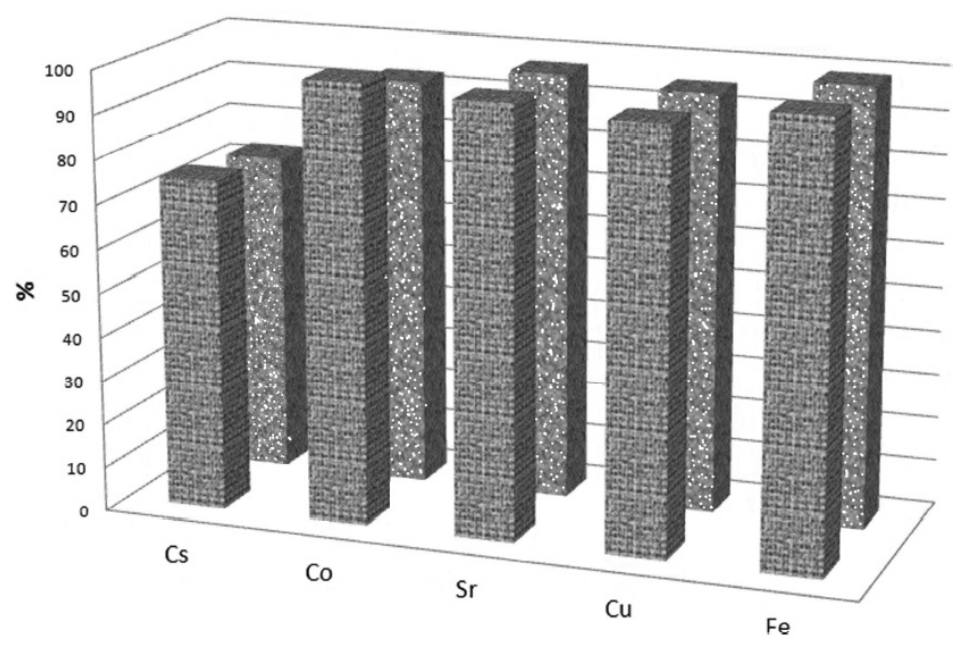

Exisy - Absorption of pollutants in the bulk of liquid radioactive waste. - Absorption of pollutants in the bulk of liquid radioactive waste in the presence of surface-active substances and borates.

Figure 3: Absorption of pollutants by the $\mathrm{SiO}_{2} / \mathrm{Fe}_{3} \mathrm{O}_{4}$ nanocomposite from multicomponent man-triggered solutions.

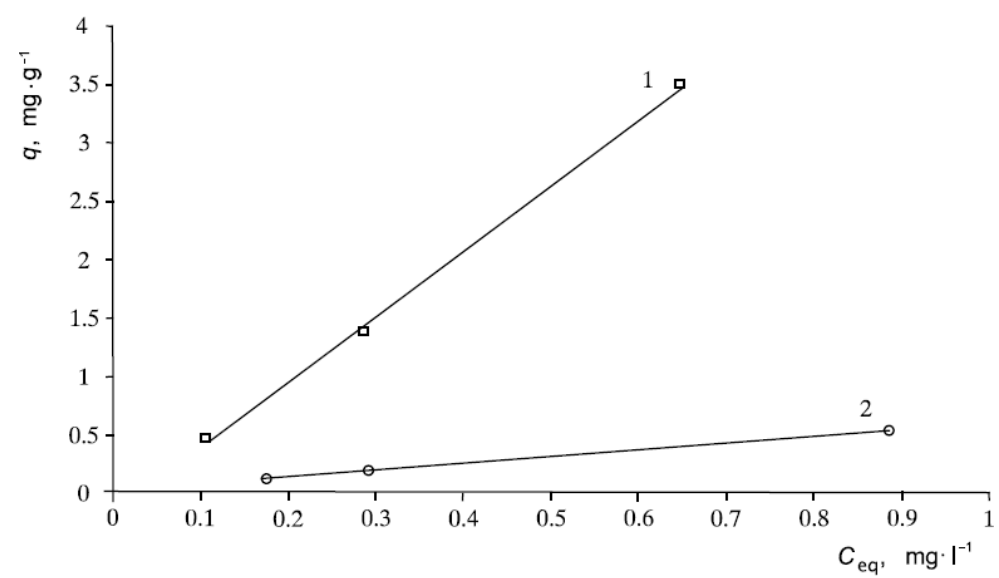

Figure 4: The absorption of $\mathrm{Cs}$ and $\mathrm{Sr}$ by the $\mathrm{SiO}_{2} / \mathrm{Fe}_{3} \mathrm{O}_{4}$ nanocomposite: $q$ is the retention capacity; $C_{\text {eq }}$ is the equilibrium concentration; 1 - absorption Cs, 2 - absorption Sr.

As can be seen from the data, about $75 \%$ of $\mathrm{Cs}, 93 \%$ of $\mathrm{Sr}, 97 \%$ of $\mathrm{Cu}$ and $99 \%$ of $\mathrm{Fe}^{+2} / \mathrm{Fe}^{+3}$ pass from dispersion medium into the solid phase per each loop of the process. 
Table 2: The absorption characteristics of the $\mathrm{SiO}_{2} / \mathrm{Fe}_{3} \mathrm{O}_{4}$ nanocomposite $\left(C_{\text {in }}\right.$ and $C_{\text {fin }}$ are the initial and final concentrations of the appropriate pollutant, respectively; $q$ is the retention capacity; $K_{\mathrm{d}}$ is the distribution coefficient).

\begin{tabular}{llllllllllllllll}
\hline $\mathbf{C s}^{\mathbf{1 +}}$ & \multicolumn{1}{c}{$\mathbf{S r}^{2+}$} & \multicolumn{1}{c}{$\mathbf{C o}^{2+}$} & \multicolumn{1}{c}{$\mathbf{F e}^{2+} / \mathbf{F e}^{3+}$} \\
\hline$C_{\text {in }}$, & $C_{\text {fin }}$, & $q$, & $K_{\mathrm{d}}$, & $C_{\text {in }}$, & $C_{\text {fin }}$, & $q$, & $K_{\mathrm{d}}$, & $C_{\text {in }}$, & $C_{\text {fin }}$, & $q$, & $K_{\mathrm{d}}$, & $C_{\text {in }}$, & $C_{\text {fin }}$, & $q$, & $K_{\mathrm{d}}$, \\
$\mathrm{mg} / 1$ & $\mathrm{mg} / 1$ & $\mathrm{mg} / 1$ & $\mathrm{mg} / 1$ & $\mathrm{mg} / 1$ & $\mathrm{mg} / 1$ & $\mathrm{mg} / 1$ & $\mathrm{mg} / 1$ & $\mathrm{mg} / 1$ & $\mathrm{mg} / 1$ & $\mathrm{mg} / 1$ & $\mathrm{mg} / 1$ & $\mathrm{mg} / 1$ & $\mathrm{mg} / 1$ & $\mathrm{mg} / 1$ & $\mathrm{mg} / 1$ \\
63 & 15.8 & 0.66 & 183 & 62 & 3.1 & 0.89 & 1589 & 42 & 2.1 & 0.6 & 1539 & 15000 & 1.5 & 599 & 79920 \\
26 & 6.5 & 0.28 & 200 & 20 & 1 & 0.29 & 1526 & 14 & 0.7 & 0.2 & 1539 & 13000 & 1.3 & 520 & 79992 \\
10 & 2.5 & 0.11 & 196 & 6 & 0.3 & 0.29 & 1526 & 4 & 0.2 & 0.06 & 1500 & 5000 & 0.5 & 200 & 79920 \\
\hline
\end{tabular}

The number of absorbed $\mathrm{Cs}$ and $\mathrm{Sr}$, which are extracted from the equilibrium concentration at $700{ }^{\circ} \mathrm{C}$, is evaluated by means of the distribution coefficient $K_{\mathrm{d}}\left(\mathrm{ml} \times \mathrm{g}^{-1}\right)$. The distribution coefficient is numerically equal to the slope of the corresponding dependency to the X-axis (Fig. 4) and is defined as the ratio of pollutants absorbed by $1 \mathrm{~g}$ of the nanocomposite to the equilibrium concentration (Table 2).

The absorption of $\mathrm{Cs}$ and $\mathrm{Sr}$, as well as $\mathrm{Co}, \mathrm{Fe}$, can be formally described by the Henry isotherm. However, it should be remembered that in addition to the adsorption of pollutants by the surface of nanoparticles of silica and magnetite, in the deposition process a co-precipitation at the formation of both the individual particles of silicon acid and magnetite, and agglomerates of silicon magnetite nanocomposite $\mathrm{SiO}_{2} / \mathrm{Fe}_{3} \mathrm{O}_{4}$ plays a significant role.

To further reduce the amount of the precipitate and to prolong isolation of absorbed elements from the environment, it is appropriate to warm the gathered elements up to $800-1000{ }^{\circ} \mathrm{C}$. Traditional technologies include application of cementing, bituminization and vitrification. Each of them has a number of drawbacks. Usually a complex processing technology is used, which includes several methods.

At the synthesis of the $\mathrm{SiO}_{2} / \mathrm{Fe}_{3} \mathrm{O}_{4}$ nanocomposite the relation between silicic acid and the amount of alkali metals has been chosen so as to ensure the formation of nanoparticles and, on the other hand, the particles obtained have to be similar in composition to glass. Warming an air-dry sample of the $\mathrm{SiO}_{2} /$ $\mathrm{Fe}_{3} \mathrm{O}_{4}$ nanocomposite to $1000{ }^{\circ} \mathrm{C}$ is accompanied by the formation of a liquid phase, which when cooled, forms a glassy amorphous phase (Fig. 5a). In the volume of the amorphous phase, crystals of $\alpha$-hematite $\left(\alpha-\mathrm{Fe}_{2} \mathrm{O}_{3}\right)$ are found (Fig. 5b) as diagnosed by the X-ray phase analysis.

Such transformations confirm studies by thermogravimetric analysis in the air (Fig. 6): an intense loss of free water at temperatures up to $100{ }^{\circ} \mathrm{C}$ has been revealed for the $\mathrm{SiO}_{2} / \mathrm{Fe}_{3} \mathrm{O}_{4}$ nanocomposite. Followed by heating in the range of $150-450{ }^{\circ} \mathrm{C}$, an intense loss of bound water is observed, which is
Nanocomposites for

Decontamination of Multicomponent Technogenic Dilutions 
Kadoshnikov, V Lytvynenko, Yu

Zabulonov, Yu

Krasnoholovets, V

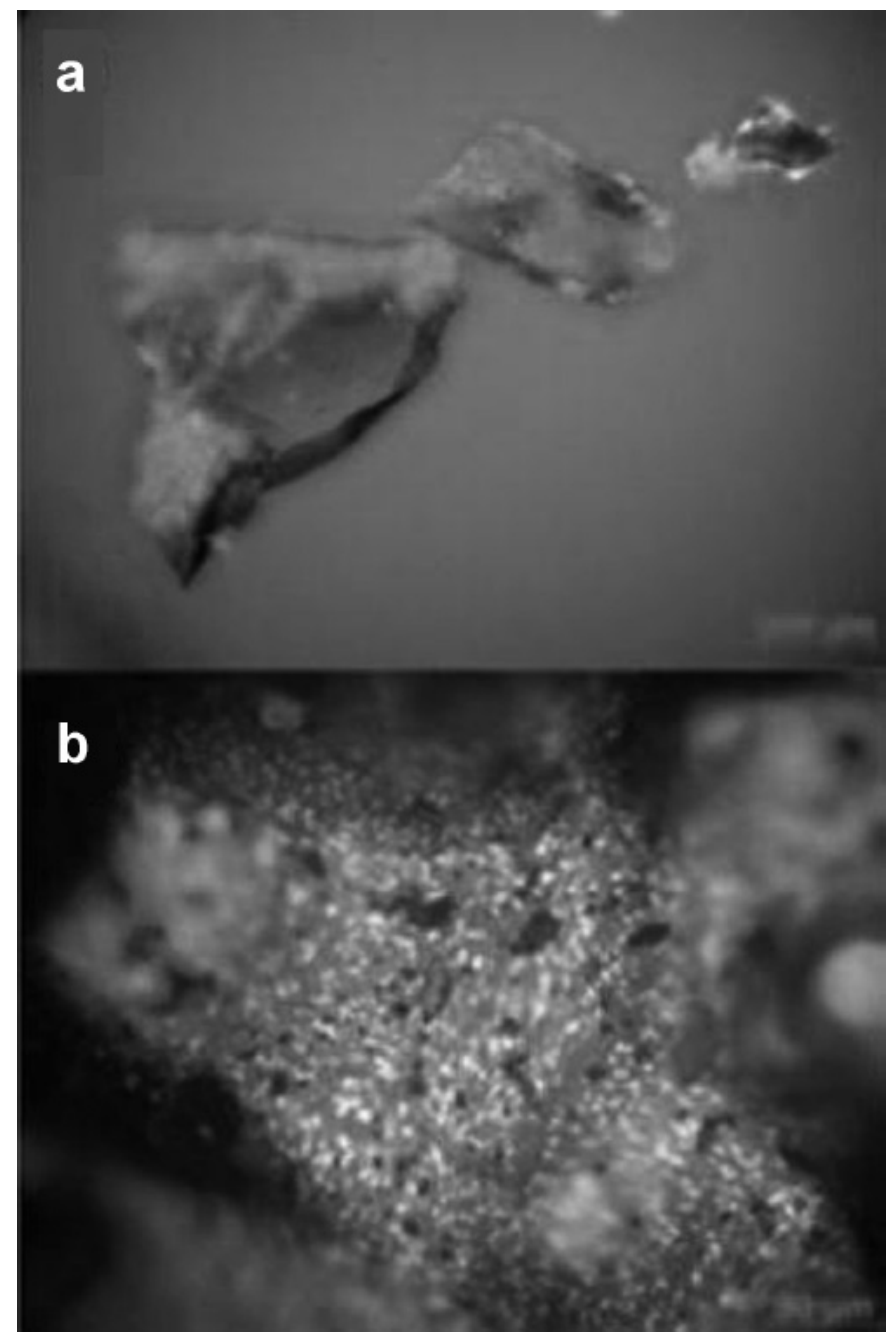

Figure 5: Pictures of nanocomposite sample $\mathrm{SiO}_{2} / \mathrm{Fe}_{3} \mathrm{O}_{4}$ withstood at a temperature of $1000{ }^{\circ} \mathrm{C}$, taken with a reflective polarizing optical microscopy.

typical for the process of dehydration of the agglomerates and the destruction of hydration shells of colloidal particles of polysilicas. A further increase in temperature above $750{ }^{\circ} \mathrm{C}$ leads to the conversion of $\mathrm{Fe}_{3} \mathrm{O}_{4}$ magnetite to $\mathrm{Fe}_{2} \mathrm{O}_{3}$ hematite by oxidation of $\mathrm{Fe}^{2+}$ to $\mathrm{Fe}^{3+}$ forming initially $\gamma-\mathrm{Fe}_{2} \mathrm{O}_{3}$, which then being exposed to a higher temperature becomes $\alpha$-hematite $\left(\alpha-\mathrm{Fe}_{2} \mathrm{O}_{3}\right)$ [17]. 


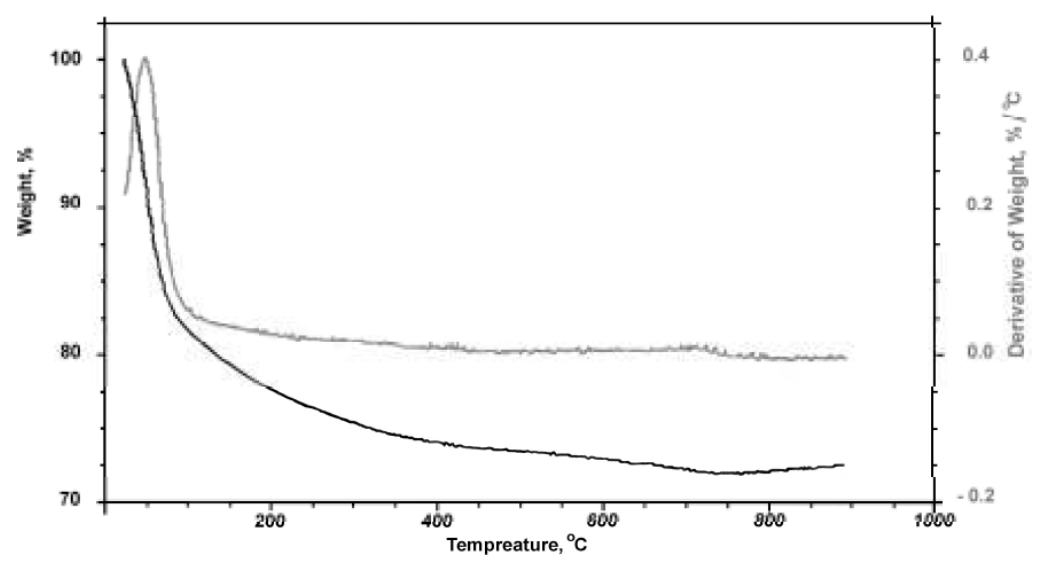

Figure 6: Weight loss and its first derivative with respect to temperature at heating of the $\mathrm{SiO}_{2} / \mathrm{Fe}_{3} \mathrm{O}_{4}$ nanocomposite sample.

\section{CONCLUSION}

The proposed method of direct sedimentation, in which $\mathrm{SiO}_{2} / \mathrm{Fe}_{3} \mathrm{O}_{4}$ nanocomposite is synthesised directly in multi-component man-triggered solutions, allows one not only to remove pollutants of different nature simultaneously, but also iteratively loop the process of deactivation over and over again.

An additional advantage of this method can be seen in the fact that the resulting $\mathrm{SiO}_{2} / \mathrm{Fe}_{3} \mathrm{O}_{4}$ nanocomposite being heated to $1000{ }^{\circ} \mathrm{C}$ forms a glass phase, which is a reliable matrix for long-term retention of radionuclides incorporated in the volume of the composite. The present study exhibits a possibility to concentrate pollutants of different nature in a small volume and then isolate them localising in a mineral glass matrix.

After a pilot testing at an actual industrial plant the present refining method may be used in vitrification technology and the compacting of radioactive and toxic waste for further secure disposal.

\section{REFERENCES}

[1] A. Kadous, M. A. Didi and D. Villemin, J. Radioanalyt. Nucl. Chem. 288 (2011) 553-561. http://dx.doi.org/10.1007/s10967-010-0970-1

[2] J. Braun and T. Barker, Nuclear Plant J., January-February (2012) pp. 36-37.

[3] J. Sun, Y. Zhang, Z. Chen, J. Zhou and N. Gu, Angewandte Chem. Int. Edition 46 (2007), 4767-4770. http://dx.doi.org/10.1002/anie.200604474
Nanocomposites for Decontamination of Multicomponent Technogenic Dilutions 
Kadoshnikov, V Lytvynenko, Yu Zabulonov, $\mathrm{Yu}$ Krasnoholovets, V
[4] G. Patzay, L. Weiser, F. Feil, G. Patek and J. Schunk, Nuclear \& Renewable Energy Conference (INREC),1st International, 21-24 March 2010, 3 pages (2010) IEEE Xplore Digital Library.

[5] L. M. Camacho, S. Deng and R. R. Parra, J. Hazard. Mater. 175 (2010) 393-398. http://dx.doi.org/10.1016/j.jhazmat.2009.10.017 PMid:19892465

[6] M. Galamboš, P. Suchánek and O. Rosskopfova, J. Radioanalyt. Nucl. Chem. 293 (2012) 613-633. http://dx.doi.org/10.1007/s10967-012-1717-y

[7] M. Lee and M. Yang, J. Hazard. Mater. 173 (2010) 589-596. http://dx.doi.org/10.1016/j.jhazmat.2009.08.127 PMid:19783370

[8] N.-E. Belkhouche, M. A. Didi and D. Villemin, Solvent Extraction and Ion Exchange, 23 (2005) 677-693. http://dx.doi.org/10.1081/SEI-200066290

[9] N. Kumari, P. Pathak, D. Prabhu and V. Manchanda, J. Hazard. Tox. Radioact. Waste, 16 (2012), 327-333. http://dx.doi.org/10.1061/(ASCE)HZ.2153-5515.0000136

[10] P. Govindan et al., Journal of Radioanalytical and Nuclear Chemistry 295 (2013) 307-313. http://dx.doi.org/10.1007/s10967-012-1831-x

[11] P. Kovařík, J. D. Navratil and J. John, Science and Technology of Nuclear Installations, Vol. 2015, Article ID 407842, 10 pages.

[12] R. K. Iler, The chemistry of silica: Solubility, polymerization, colloid and surface properties and biochemisry of silica, John Wiley and Sons, Chichester (1979).

[13] R. O. Abdel Rahman, H. A. Ibrahium Y.-T. and Hung, Water 3 (2011) 551-565. http://dx.doi.org/10.3390/w3020551

[14] S. Chitra et al., J. Radioanalyt. Nucl. Chem. 295 (2013) 607-613. http://dx.doi.org/10.1007/s10967-012-1812-0

[15] S. S. Voyutskiy The course of colloid chemistry, Khimia, Moscow (1975), p. 512 (in Muscovian).

[16] V. Valdovinos, F. Monroy-Guzman and E. Bustos, Ed.: M.C. Hernandez-Soriano, InTech, Chapters published March 26, 2014 under CC BY 3.0 license, Open Access Book (2014) Ch. 14, http://cdn.intechopen.com/pdfs-wm/46254.pdf; doi: 10.5772/57086INTECH

[17] W. W. Werdlandt, Thermal methods of analysis, Mir, Moscow (1978) (Muscovian translation).

[18] W. Zou, H. Bai, L. Zhao and K. L. R. Han, J. Radioanalyt. Nucl. Chem. 288 (2011) 779-788. http://dx.doi.org/10.1007/s10967-010-0904-y

[19] Yu. Zabulonov, V. Kadoshnikov and Yu. Lytvynenko, Patent of Ukraine No. 77123 (2012).

[20] Yu.Zabulonov, Yu. Lytvynenko, V. Kadoshniko and S. Kuzenko, Anthropogenic and environmental safety and civil protection, Kyiv - Kremenchuk (2011), 3, p. 201 (in Ukrainian).

[21] Yu. Zabulonov, Yu. Lytvynenko, V. Kadoshnikov and I. R. Pysanska, Collection of scientific works "Modeling and the information technologies", Kyiv: Institute for Simulation and Information Technology, Natl. Acad. Sci. of Ukraine, 59 (2011) 116-125. 